\title{
Apprehension and Pedagogy in Evolution Education
}

\author{
Brian Alters
}

Published online: 20 April 2010

(C) Springer Science+Business Media, LLC 2010

\begin{abstract}
Instructors' apprehensions and the decisions instructors make about pedagogy are often linked when it comes to teaching evolution. Whether it is the reticence of K-12 teachers that their instruction may affect their students' religious beliefs detrimentally or that they may become caught up in some administrative, media, parental, or school political turmoil or whether it is the apprehension of college students who perceive that their religious beliefs are being explicitly challenged, such fears can be reduced by understanding their roots and by honing pedagogy in ways that reduce perceived threats. This article describes why it is prudent to address these often secretly held apprehensions and how to help instructors feel free to employ their best pedagogical methods to teach evolution without lingering fear. Some suggestions are given for precollege and college instructors interested in combining effective pedagogy with as little perceived threat as possible. Methods are offered that allow instructors to focus on underlying scientific misconceptions even if those misconceptions are ultimately facilitated by non-scientific sources, while giving creationist or creationist-leaning students a chance to learn the appropriate scientific conceptions without their religious beliefs being explicitly threatened in a science course.
\end{abstract}

Keywords Evolution education · Religion · Intelligent design $\cdot$ Creationism $\cdot$ Teachers $\cdot$ Schools $\cdot$ Science $\cdot$ Students

B. Alters $(\bowtie)$

Redpath Museum, McGill University,

859 Sherbrooke Street West,

Montréal, QC H3A 2K6, Canada

e-mail: brian.alters@mcgill.ca
"The chief danger to evolution education comes ... from teachers just quietly ceasing to teach evolution because it is too controversial." Eugenie C. Scott (1997: 285)

Along with having a host of other responsibilities, Eugenie Scott, working as the executive director of the National Center for Science Education, has been involved with discussions of what teachers should know about science pedagogy in general and with methods for allaying teacher apprehensions about teaching the subject of evolution in particular. With such apprehensions frequently impinging on effective teacher pedagogy, I will begin this essay in her honor by addressing these often secretively held teacher apprehensions and then look at some pedagogical suggestions.

\section{Teacher Apprehensions}

Because the science of evolution is often perceived as being inextricably antagonistic to religion, untold numbers of teachers hold minor-to-significant concerns - often fears about what effect their teaching of evolution may have on their students' religious beliefs and, subsequently, on the dynamics within students' families.

To be sure, most science teachers are well aware that evolution should be taught because it concerns our biological origins, is good science, is in the textbooks, is in the curriculum, and is in the state and national standards. For these reasons, the decision to teach evolution is an imperative for most science teachers. Nevertheless, for other reasons, a great number of those same teachers perceive that a huge moral dilemma is at hand: whether to teach evolution competently because that is the duty of a 
good science teacher or to teach it ineffectively - or not at all - because the teaching of evolution may detrimentally affect students' religious beliefs. ${ }^{1}$

In both Canada and the United States where I hold appointments at McGill and Harvard universities, I have had the privilege of teaching science education, and particularly evolution education, to thousands of preservice and in-service elementary and secondary school science teachers. Over these years a significant portion of the teachers have personally confided in me, and a large number of others have reported through anonymous surveys, that they are concerned about interfering with the religious beliefs parents are instilling in their children. It is not that these teachers necessarily concur with the parents' choices of religious upbringing: it is a matter of potentially undermining what the teachers feel is solely the parental purview - religious education. Moreover, these teachers feel that they would not want the teachers of their own children to directly contradict something as important and personal as the family's religion (e.g., Asghar et al. 2007).

In response to this concern, the most obvious point is that no goal or objective of a K-12 public school teacher or curriculum should be designed intentionally to detract from or advance any religion. For example, to have lesson objectives of understanding that the religious belief of intelligent design is faulty or having students able to list $X$ number of reasons why the religious belief of intelligent design is faulty would be wrong. With these objectives, there is a clear intent to cause change in religious belief.

However, things become muddled for many compassionate teachers who have no intention of changing their students' religious beliefs but who worry that their teaching of evolutionary science indirectly causes such change even though their teaching objectives are focused solely on increasing student understanding of evolutionary science.

One possible defense from moral philosophy is the widely discussed doctrine (or principle) of double effect. It essentially permits an action that causes a serious harm as a side effect of promoting some good end (McIntyre 2009). Applied in this case, it basically states that it would be permissible to teach evolution - even though the teacher foresees that religious change may be a side effect (or "double effect") - as long as the intention is not religious change, but rather greater student understanding of evolution. This may certainly help teachers who regard the importance of learning evolution as outweighing the (assumed) harm done to student religious belief. On the other hand, there

\footnotetext{
${ }^{1}$ Naturally, it would be just as inappropriate for public school teachers to craft instruction with the intent to improve or reinforce their students' religious beliefs as it would be to craft instruction with the intent to detract from their students' religious beliefs. However, the teachers being discussed in this article are concerned only about possibly detrimentally affecting their students' religious beliefs.
}

are compassionate teachers who do not regard the importance of learning evolution as outweighing the (assumed) harm done to student religious belief. Sometimes these teachers say that the minority of their elementary or high school students that eventually become college science majors can learn about evolution as adults when they can better decide about their religious views. They are not willing to allow the double effect to occur on their watch, however. ${ }^{2}$

The deeper issue here is with the assumption that these compassionate teachers make: that their teaching of evolution is going to be a primary cause of change in their students' religious beliefs. After all, teaching evolution effectively is commonly thought to lead to a greater understanding of evolution, and it's frequently believed that a greater understanding of evolution will produce a change in religious belief. Causation is often thought to be strictly transitive: if A causes B, and B causes C, then A causes $\mathrm{C}$. So it is understandable that conscientious teachers and to-be teachers feel that they will cause religious change if they teach evolution effectively. But in fact the assumption is wrong, and doing away with this faulty assumption has helped instructors feel free to employ their best pedagogical methods to teach evolution without the lingering fear. So why is the assumption wrong?

First, there are many factors at play - in one proportion or another - in any change of a student's religious views, and even the most conscientious educator cannot take responsibility for all of them. Consider, for example, that high school students are usually experiencing increases in their religious literacy, their tendency to independent thinking, their willingness to challenge authorities, and their exposure to people with differing points of view on religious matters. All of these may contribute to a change in a student's religious views, independently of what they are learning in their biology classrooms. Even if increasing understanding of evolution is a sufficient condition of a change in religious belief, the change might have occurred anyhow.

Second, there simply is not any solid evidence that increased evolution understanding is a sufficient condition of change in religious belief. I have yet to see a good study that demonstrates even a correlation. However, even if such a study does exist, correlation does not prove causation. For

\footnotetext{
${ }^{2}$ If these teachers were educated further - to understand, for example, that it really is important even for students not pursuing biology degrees in college to understand evolution, that many religious traditions have accommodated evolution within their systems of belief, that evolution has practical applications in agriculture, medicine, etc. - then perhaps they would agree that it is permissible to teach evolution despite the risk of affecting students' religious beliefs and thus be reassured. However, there are still teachers who, despite having such further education (which is highly recommended), nonetheless feel "preserving" their students' religious beliefs trumps evolution education.
} 
example, perhaps young people who have more open minds about evolution tend to have more open minds about changes in their religious belief. Maybe the greater student understanding of evolution is an epiphenomenon. To demonstrate that increased understanding of evolution causes change in religious belief, we would have to run a true experiment: Take a large sample of students and randomly divide them into two groups, then have one group increase their understanding of evolution and the other group abstain from increasing their understanding of evolution. If the first group of students has religious belief changes and the other group does not, the claim can be made that increased evolution understanding is the cause. Obviously, such experiments would be fraught with methodological complications and grossly unethical.

Thus, no one can rightly say that teaching evolution causes change in religious belief, and thus we can all - even the most conscientious of teachers among us - employ our best pedagogical methods to teach evolution. ${ }^{3}$

So can all teacher apprehension regarding evolution instruction now be put to rest? ${ }^{4}$ Not yet, say a whole other crowd of apprehensive pre-service and in-service K-12 teachers. Worry concerning a causal connection between greater understanding of evolutionary science and change in student religious belief aside, many teachers are concerned about a potential backlash caused by merely teaching evolution - effectively or not. They fear not only a hostile response from parents, fellow teachers, principals, or school boards but also the potential of getting caught up in media reports about the goings-on in their relatively out-ofthe-way classrooms. These fears have nothing to do with whether the teacher facilitates a greater understanding of evolutionary science among the students but, instead,

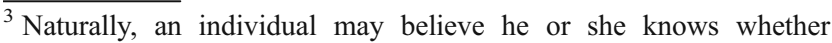
understanding evolution better caused a change in his or her own religious views; however, a sample size of one is insignificant for causal determinations. And even if large numbers of students reported that understanding evolution caused a change in their religious beliefs, causal self-reporting is notoriously imprecise, and those who selfreport are often unaware of additional determining causes, conditions, enablers, multiple statistically significant causes, and other threats to the validity of such claims for the purposes of research determinations. And even if students believe they have narrowed down the conditions of their religious change to its "one cause" (increased evolution understanding) and some mere enablers or helpers, such reporting is suspect. For example, Harvard's renowned professor of Psychology Steven Pinker reports that "People somehow distinguish just one of the necessary conditions for an event as its cause and the others as mere enablers or helpers, even when all are equally necessary" (Pinker 2007, 214).

${ }^{4}$ Alas, I believe many teachers will not find my arguments persuasive; nevertheless, some have and others will find them useful. Because teachers are a diverse population, what works for one will likely not work for all. We must chip away at their fears little by little if necessary.
}

with the mere action of exposing students to the concept. Maybe the students will learn next to nothing - or perhaps nothing - about evolution. That is not the point. The fear stems from the act of presenting evolution as opposed to not presenting evolution and the resultant turmoil that may put the teacher in the middle of an unwanted controversial spotlight (Alters 2006).

Most K-12 teachers I know of through my teaching, research, and reading went into teaching because they like teaching, students, and the curricular subjects. They did not sign up to become teachers to have adversarial attention thrust upon them by those who should be supporting them and then have that conflict reported in the media. Because of their apprehension to a backlash concerning their teaching, untold numbers of teachers diminish their evolution instruction in a variety of ways, from using less pedagogically effective methods to truncating the "coverage" to substituting misleading substitutes such as "change over time" for the e-word to eliminating the subject altogether.

It is not just self-protection from a media storm that causes many to take these actions - for some it is a matter of appeasement. Some teachers are motivated not as much by apprehension as by finding appeasing "middle ground" after they receive parental pressure (NSTA 2005; Wiles and Branch 2008). And in some instances it is principals attempting to keep the peace between parents and their schools that want the "middle ground." The stories go something like this: Competent teachers are dutifully utilizing effective pedagogical methods when parents visit the teachers for an afterschool chat. The parents explain their displeasure that evolution is being taught to their children - and to other children in the class - and request that the teacher acquiesce. The dutiful teachers explain to the parents why evolution should be taught to their children - and to all children - in the most kind, logical, accurate, and understanding way. (These types of responses will be discussed later in this article.)

Alas, the parents are not convinced that evolution should be taught and have a meeting with the principal. It has been my anecdotal experience with hundreds of school principals that the vast majority do not have science backgrounds. This point is rather glaring when the principals, after having met with the complaining parents, attempt to keep peace between parents and the schools by attempting to persuade the teachers to find some "middle ground," diminish the teaching of evolution, or eliminate it altogether. ${ }^{5}$ This is

\footnotetext{
${ }^{5}$ Principals: I am only referring here to the principals that have acquiesced to parental pressure, not the vast majority of excellent principals who properly defend their teachers regarding evolution instruction.
} 
where subtle and widely varying politics within the schools are frequently at work: noncompliant teachers are viewed as not "helping out" principals with parental problems.

Clearly, both principals and teachers want good science education and peace at their schools. However, typically, principals must face parental wrath with more intensity and frequency than teachers because parents complain up the ladder to the on-site "boss." Principals think that teachers should be willing to help out their principals, the schools, and the parents by "giving in" a little. These teachers then become troubled by school politics involving their bosses and possibly even other employees in the schools' or districts' political webs. They find themselves in an untenable situation involving their day-to-day working relationships, conditions, performance reviews, and so forth.

Somehow we teachers must overcome our troubling concerns and apprehensions - whether they involve parental conflicts with accompanying media and legal backlashes, principals' well-meaning desires to keep parentschool peace by misguidedly pressuring science teachers to use less effective pedagogy, or any other of the variety of concerns and apprehensions that exist. There are long replies to help lessen these problems in addition to my brief comments here, but they would never fit within the few pages of this article. However, there is - thankfully one excellent concise response to science teachers' concerns about teaching evolution effectively. That response is to go to places who offer help (e.g., NCSE, NABT, and NSTA). We are not alone! The NCSE specializes in defending the teaching of evolution and stands ready with a wide array of experience and resources to help when called upon. They do everything in their power to protect the anonymity of the people who need help. Before you, or others that you know, give in to pressure, fear, or other discomfort, contact one or more helpful organizations for advice. You, and ultimately your students, will be glad you did.

\section{Pedagogical Suggestions}

I mentioned previously that, when teachers are first broadsided by parent requests to diminish or eliminate evolution instruction, the dutiful teachers explain to the parents why evolution should be taught to their children. It is important that parents know why evolutionary science is essential. The concise answer goes something like the following:

So why should your child learn evolution? Eliminating evolution from your child's education removes the context and unifying theory that underpins and permeates the biological sciences. Your child thus learns disparate facts in the science classroom without the thread that ties them together, and misses the answers to its underlying why questions. Without an understanding of evolution, your child cannot understand processes based on this science, such as insect resistance to pesticides or microbial resistance to antibiotics. Your child will not come to understand the macro-evolutionary history of the planet, connections to other scientific fields, nor will your child fully understand the world of which we are apart. Evolution is, in fact, one of the most important concepts in attaining scientific literacy (Alters and Alters 2001: 112).

If the parents want to hear a more authoritative reply with respect to developmental psychology of children, then the following from Howard Gardner, Professor, Harvard Graduate School of Education, is one of the best:

This is an important area of science, with particular significance for a developmental psychologist like me. Unless one has some understanding of the key notions of species, variation, and natural selection, adaptation, and the like (and how these have been discovered), unless one appreciates the perennial struggle among individuals (and populations) for survival in a particular ecological niche, one cannot understand the living world of which we are a part (Gardner 1999: 16).

I assume that most people reading this article are inservice or pre-service $\mathrm{K}-12$ teachers that have taken teaching methodology courses, so I will not reiterate what you probably know. And hopefully you have read some of this journal's recent special issue on teaching evolution (September 2009). For college instructors who typically never had any teaching methodology courses, this limited space cannot scratch the surface of a good college course in teaching methods. Nevertheless, parts of what follows will hopefully be useful to all instructors no matter what the level.

There is a continuum of pedagogical techniques that range from the relatively ineffective to the relatively effective. This fact helps explain that significant numbers of students often do not learn the evolutionary concepts they are taught. Combine ineffective pedagogy with some students' perceptions that evolution instruction threatens and is diametrically opposed to their religious beliefs and it's not surprising that they leave science class lacking even the most rudimentary understanding of evolution.

The trick is to combine good pedagogy with as little perceived threat as possible. For example, in one type of instructional constructivist approach familiar to teachers, the essential elements could be summarized in four steps as 
follows - but with some added bracketed evolutioninstruction advice:

1. Questions should be raised or problems should be posed that require students to act on the basis of prior beliefs (concepts and conceptual systems) or prior procedures. [These questions or problems should be about scientific misconceptions, not intelligent design, scientific creationism, or any other religious belief by name.]

2. Those actions should lead to results that are ambiguous or can be challenged or contradicted. This forces students to reflect back on their prior beliefs or procedures used to generate the results. [Instructors must help students reflect on their prior "scientific" conceptions or procedures, not on their prior religious conceptions or procedures. For example, regarding a young earth misconception, the students should reflect on misconceptions about the "fallibility" of modern fossil dating techniques, never to scriptural references or other religious authority.]

3. Alternative beliefs or more effective procedures should be proposed by students and the teacher. [Naturally, the instructor must allow only scientific alternative concepts to be proposed. If religious alternative concepts are proposed by students, the teacher needs to offer instruction concerning the nature of science and thus why religious alternative concepts are not science concepts. Never should the teacher even appear to suggest that the religious alternative concept is somehow inaccurate (or accurate). The religious concept should not be adjudicated in the science classroom, merely respectfully excused from the inquiry for not being science.]

4. Alternative beliefs or the more effective procedures should now be utilized to generate new predictions or new data to allow either the change of old beliefs or the acquisition of a new belief (concept). [This change is not a change from intelligent design or scientific creationism to some non-intelligent design or nonscientific creationism position; rather, it's from some specific scientific misconception to an appropriate scientific conception - such as complex biological structures could not have developed gradually, to a concept whereby gradual processes could produce such structures] (Lawson 1994: 116).

Various teaching methods appear beneficial in accomplishing all four of these goals but the bracketed portions are most authoritative to public school pre-college teachers, primarily because of the legalities concerning religion in those schools. At the public school K-12 level, none of the pedagogy can be used legally to detract from (or advance) student religious beliefs. Nevertheless, even though most college professors have the freedom to address whatever they feel is prudent within their science courses - even religious concepts - the parenthetical advice should work just as well for college courses as it does for pre-college courses. It allows the professors to focus on underlying scientific misconceptions even if those misconceptions are ultimately facilitated by non-scientific sources, while giving the creationist or creationist-leaning students a chance to learn the appropriate scientific conceptions without their religious beliefs being explicitly threatened in a science course. For research-based pieces on teaching evolution in higher education, see Alters and Nelson (2002) and Alters (2005).

Whether it is the apprehension of K-12 teachers about being caught up in some unwanted administrative, media, parental, or school political mess or the apprehension that some students feel at the college level that their religious beliefs are being explicitly challenged, apprehensions can be reduced by understanding their roots and by honing pedagogy in ways that reduce perceived threat. Thus, students and science teachers can both have a more enjoyable and productive learning experience.

\section{References}

Alters B. Evolution in the classroom. In: Scott EC, Branch G, editors. Not in our classrooms: Why intelligent design is wrong for our schools. Boston: Beacon; 2006. p. 105-29.

Alters B. Teaching evolution in higher education: Methodological, religious, and nonreligious issues. Sudbury: Jones \& Bartlett; 2005.

Alters B, Alters S. Defending evolution in the classroom. Sudbury: Jones \& Bartlett; 2001.

Alters B, Nelson CE. Teaching evolution. Evolution Int $\mathrm{J}$ Org Evolution. 2002;56(10):1891-901.

Asghar A, Wiles J, Alters B. Canadian pre-service elementary teachers' conceptions of biological evolution and evolution education. McGill J Educ. 2007;42(2):189-209.

Gardner H. The disciplined mind: What all students should understand. New York: Simon and Schuster; 1999.

Lawson AE. Research on the acquisition of science knowledge: Epistemological foundations of cognition. In: Gabel DL, editor. Handbook on research on science teaching and learning. New York: Macmillan; 1994. p. 131-76.

McIntyre A. Doctrine of double effect. Stanford Encyclopedia of Philosophy. 2009. http://plato.stanford.edu/entries/double-effect.

NSTA. Survey indicates science teachers feel pressure to teach nonscientific alternatives to evolution. 2005. http://www.nsta. org/about/pressroom. aspx?id=50377.

Pinker S. The stuff of thought. New York: Penguin Books; 2007.

Scott EC. Antievolution and creationism in the United States. Annu Rev Anthropol. 1997;26:263-9.

Wiles J, Branch G. Teachers who won't, don't, or can't teach evolution properly: A burning issue. Am Biol Teach. 2008;70(1):6-7. 